\title{
Ensuring health, safety and well-being on the UK's Thames Tideway tunnel programme
}

1 Andy Alder MEng, MSc, CEng, FICE, FAPM, FRGS Programme Director, Tideway and Vice President Major Programmes, Jacobs, London UK (corresponding author: andy.alder@jacobs.com)

2 Steve Hails MSc, CMIOSH Business Services and Health, Safety and Wellbeing Director, Tideway, London, UK
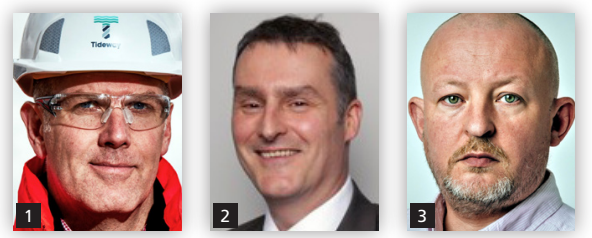

3 Alex Vaughan MIIRSM, MInstLM, MIIAI

Head of Health and Safety, Ferrovial Laing O'Rourke Joint Venture Tideway Central, London, UK

Due for completion in 2025, the $\mathbf{f} \mathbf{4 . 2}$ billion Thames Tideway tunnel programme is one of the largest and most complex civil engineering schemes in the world. This paper reports on how the delivery team ensured the health, safety and well-being of over 4000 people who worked on the programme during the first 6 years of its 9 year delivery. The team collaborated to create a strong safety culture, focusing on excellence in getting the basics right, sharing and adopting best practice, and learning from near misses and incidents. The result has been a very good level of safety performance.

Keywords: health \& safety; major project; marine construction; safety \& hazards; tunnels and tunnelling; UN SDG 3: Good health and well-being; UN SDG 9: Industry, innovation and infrastructure; UN SDG 14: Life below water

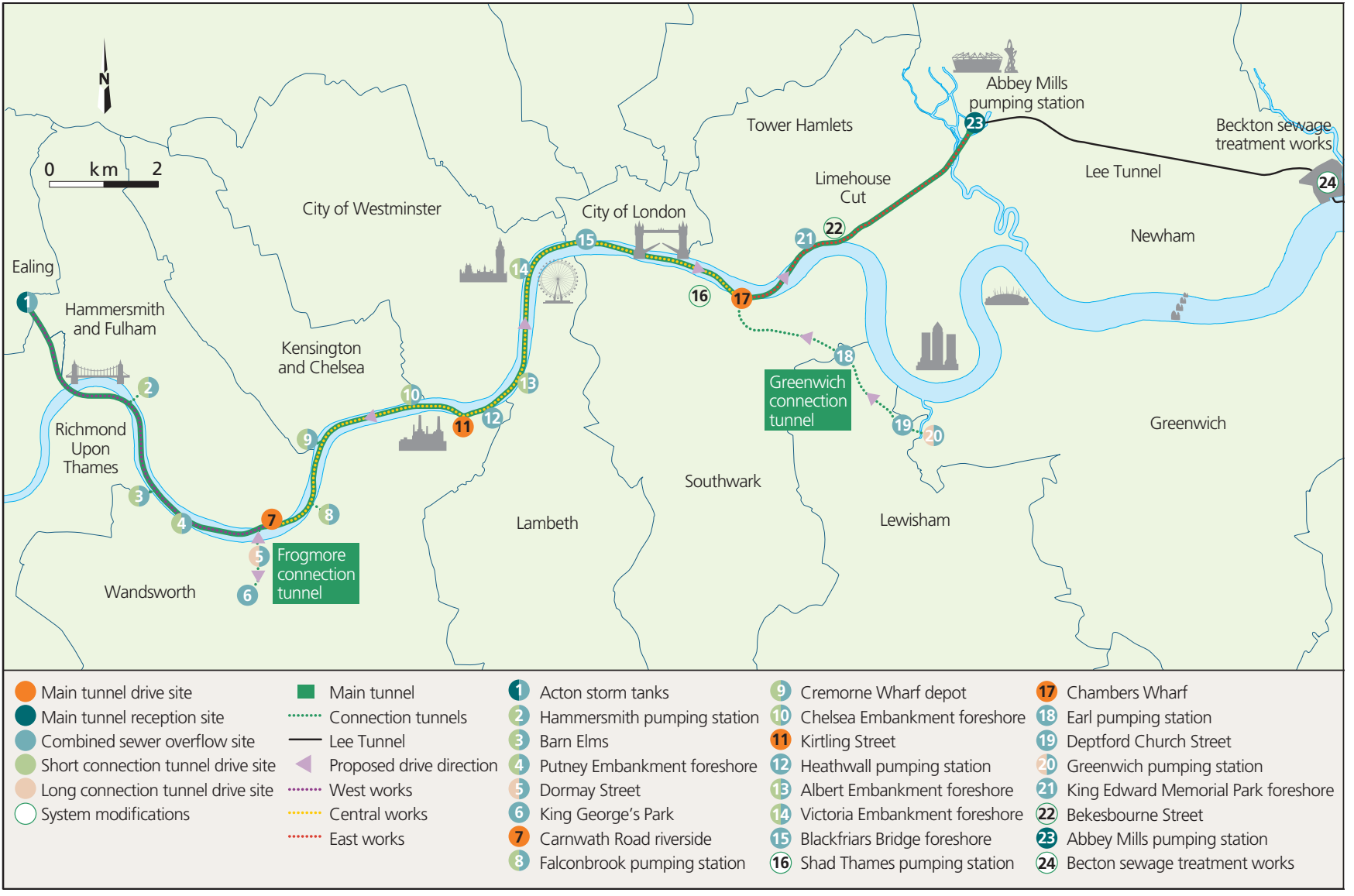

Figure 1. Plan view of the Thames Tideway tunnel programme 


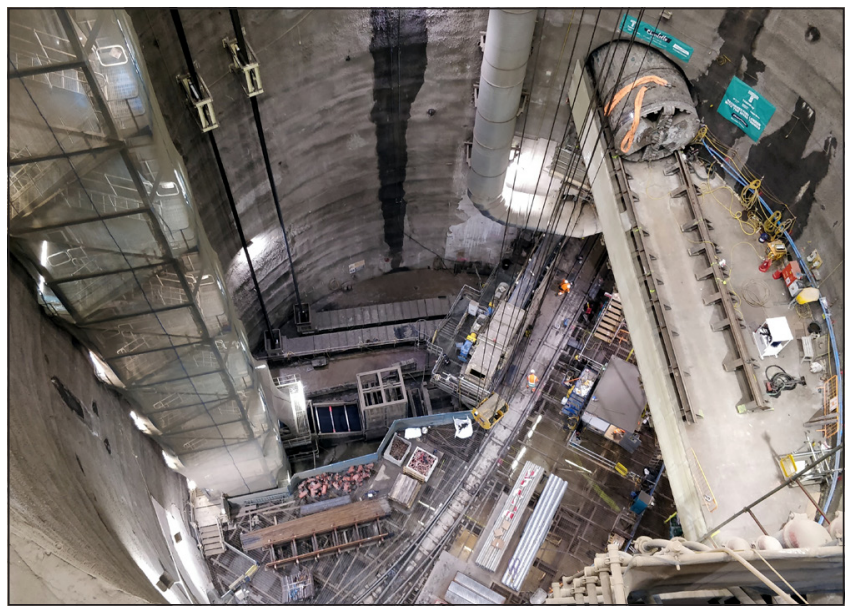

Figure 2. Carnwath Road main tunnelling shaft, showing reception for the Frogmore connection tunnel boring machine

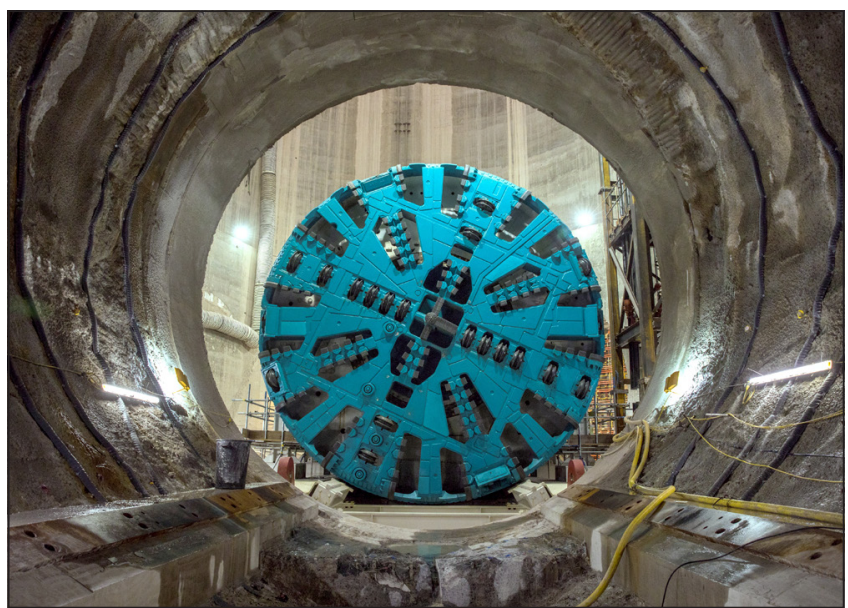

Figure 3. Launch of one of the main tunnel boring machines, which operated at depths of up to $60 \mathrm{~m}$

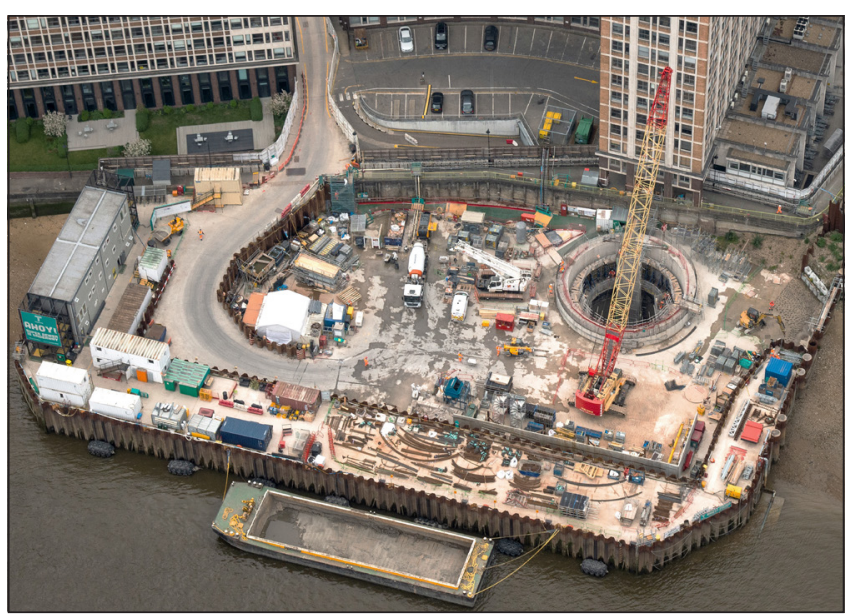

Figure 4. Cofferdam to create the Albert Embankment work site in the River Thames

\section{Introduction}

London's combined sewerage system was developed by Sir Joseph Bazalgette over 150 years ago, when the population of London was approximately 2 million people (Bazalgette, 1865; Haliday, 2001). While the system was designed for twice this, the population has continued to grow and is now at around 9 million. This, combined with the extent of impermeable paving creating quicker surface water run-off, means the capacity of the existing storm sewer network is exceeded during rainfall events and excess sewage is discharged into the River Thames through a series of combined sewer overflows (CSOs). Currently around $40 \mathrm{Mt}$ of untreated combined (foul and storm) sewage is discharged into the river each year, which is damaging to the aquatic ecosystem, is harmful to fish breeding and creates obvious public health impacts.

The $£ 4.2$ billion Thames Tideway tunnel programme is currently being constructed to intercept the CSOs during storm events (Alder 2021; Alder and Appleton, 2017; Stride, 2016; Stride and Bazalgette, 2019). The intercepted sewage can then be stored in the so-called 'super sewer' tunnel and pumped through Thames Water's sewage treatment works at Beckton. The programme comprises the following (Figure 1).

- A $25 \mathrm{~km}$ long main tunnel from Acton to Abbey Mills, mainly following the route of the Thames. At Abbey Mills the main tunnel connects with the previously constructed Lee tunnel (Costes et al., 2018).

- $5.5 \mathrm{~km}$ of additional connection tunnels through Wandsworth (Frogmore connection tunnel) and to Greenwich (Greenwich connection tunnel).

- 17 sites where CSO interception shafts and structures are being built to intercept sewage flows and carry them into the main tunnel.

Tideway as a delivery organisation was formally established in 2015 , with Jacobs appointed as the programme and project manager. Main works design-and-construct contracts were awarded to a Bam Nuttall, Morgan Sindall and Balfour Beatty joint venture (west), a Ferrovial and Laing O'Rourke joint venture (central) and a Costain, Vinci and Bachy joint venture (east), with Amey appointed as the systems integration contractor. Tideway is the client under the UK Construction Design and Management (CDM) Regulations (HMG, 2015), Jacobs is the CDM principal designer and the three main works contractors are the CDM principal contractors. Construction work started in 2016 and the majority is forecast to be complete in 2023 , with testing and commissioning in 2024 and full operational service in 2025.

At depths of between $35 \mathrm{~m}$ and $60 \mathrm{~m}$, the shafts and tunnels are among the deepest ever constructed in London (Figures 2 and 3). They intercept all the stratigraphy below London from the made ground down to the underlying chalk and require construction in water pressures up to 6 bar $(600 \mathrm{kPa})$. Establishing the worksites needed extensive marine civil engineering to create cofferdams in the river (Figure 4), and construction of the sewer interception structures requires working within strategic operational sewers. It is clear that the works required for the programme are high risk and safety critical.

All the organisations involved have been committed to achieving a health, safety and well-being performance that is transformational, 
exceeding that attained on recent major projects in which many members of the teams had been involved. A further aspiration is that when completing their roles on Tideway, people will be more competent and healthier. They will have higher expectations of safety and well-being standards that they will take on to their next projects. This paper explains the approaches that have been used on Tideway to try to achieve those aims.

\section{Defining transformational health, safety and well-being}

Having set a vision to be transformational, the delivery team needed to define in practice what that meant. Representatives from all organisations joined together to form the transformational health and safety group. Within this group it was agreed that the vision would be achieved through three strands.

- Adopting industry best practice in health, safety and wellbeing as minimum standards from the outset - in other words, adopting excellence in getting the basics right.

- Establishing a culture and organisational arrangements to develop, share and implement best practice further.

- Seeking out and adopting innovation that could further enhance safety, health and well-being.

The group was clear that the first strand was the foundation to which the second and third strands could be applied. Having the foundation of excellence in standard procedures was essential to securing further marginal gains from best practice and innovation. To that end, the group collaborated to define and commit to a set of minimum requirements that would be applied as works mobilised. These commitments included standards related to: induction and onboarding, training, supervision, site set-up, communications and behavioural safety, design and planning, safety management systems, health and well-being, and incident management.

As the programme progressed, the method of implementing the strands has developed and changed, but the intent has remained. These commitments greatly assisted in establishing a high standard of health, safety and well-being on site from the start.

\section{Programme induction}

Team capability and culture are fundamental to achieving excellence in health, safety and well-being performance, and to any other aspect of programme performance. Team capability was routinely being addressed through the selection of organisations and teams who had the experience and competence necessary to plan, design and deliver the highly complex programme scope.

To help enable the right culture to be formed and maintained as people joined the programme, the client designed and implemented the 'employer's project induction centre' (Figure 5). This is an immersive induction experience where, through a combination of film and acting, people experience a simulated accident on a site and the actions, decisions and behaviours that led to that accident occurring. The film and acting continue to highlight the impact that a construction accident has on someone's family for many years afterwards.

The induction also includes a series of workshops to discuss how a positive safety culture is formed and to train people in the skills to challenge constructively unsafe conditions and unsafe behaviours. This is reinforced by an in-person message from one of the senior leadership team, making it clear that everyone has the right and obligation to intervene or to stop their activity if they feel unsafe, and that they will be fully supported by the leadership team on their site. The message reinforces the commitment that the programme has to people's safety, and in turn the personal obligation everyone has for health, safety and well-being.

The safety culture is introduced on day one, but it needs to be reinforced continually by actions across the whole team. Having everyone attend the induction creates a strong starting position, with expectations set clearly and providing a common reference point for conversations as people move to the various programme offices and construction worksites.

In support of the safety culture, the programme's safety programme was branded as 'RightWay'. This was designed to be clear and simple, with the message that things will be done the right way: safety and well-being is a fundamental ethical responsibility and will take priority over pressures such as schedule and cost. It is also a message that can be transferred to other important aspects of the work: for example, building quality assets that will function properly and be durable, protecting the environment and developing the programme in a sustainable way, and taking care when working in the communities surrounding the sites.

\section{Project facilities and personal protective equipment}

Excellence in health, safety and well-being is fundamentally based on creating a culture of caring. A tangible and important aspect of this is providing high standards of site facilities, a clean and safe working environment and good quality personal protective equipment (PPE). A key message at the induction is that everyone is expected to do their best to look after themselves and their

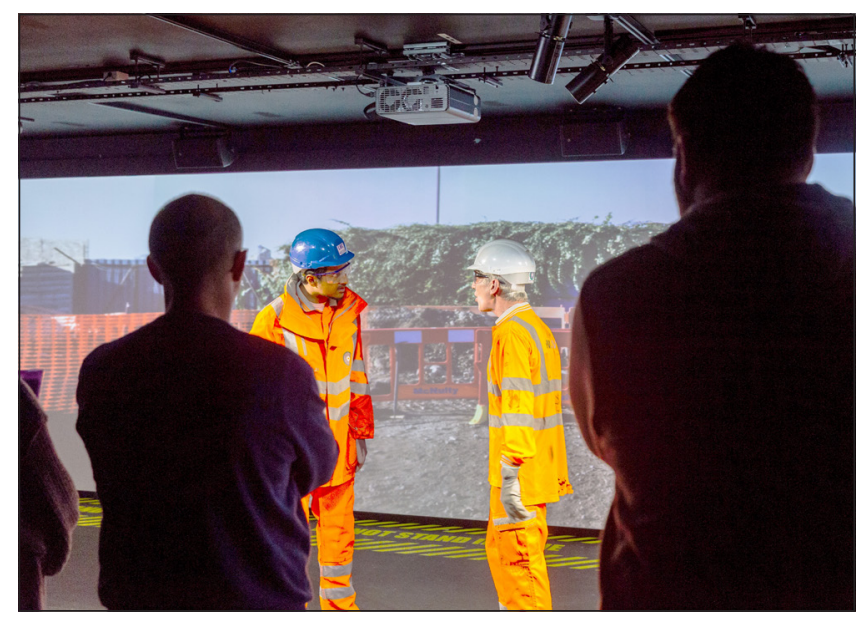

Figure 5. Project induction centre provided an immersive experience for joiners, including simulated accidents 
colleagues. In return, everyone can expect high standards of site facilities and equipment. The intent was that, on arriving on site, all new joiners to the programme would recognise the importance placed on their welfare through the equipment and facilities provided.

To ensure the aim was achieved, the transformational health and safety group developed a set of jointly agreed minimum standards for site welfare facilities and site offices, so that consistent high standards would be met across the programme. In developing these standards, the views of a number of the workforce on current live projects were obtained. The requirements included the space and facilities for changing and showers, canteen areas and site offices, with the intent to provide facilities to the same standard expected in a permanent office building.

A specific requirement was to have sufficient designated spaces for briefings, with good audio-visual equipment, so that briefings could be effectively delivered to the teams. The main contractors worked hard with their suppliers to translate these requirements into practice, and part of the process was to hold a collaborative review between the main contractor, client and project manager prior to mobilising at each site to agree how the jointly agreed minimum standards would be fulfilled.

Similarly, the transformational health and safety group also agreed a specification for the PPE to be supplied. Part of this was to have a colour scheme that was unique to the programme - dark orange and teal - to help create the pride and association towards the programme. More importantly, the quality of the PPE was set at a high standard so that people were happy to wear it, the fit was good and it was durable. PPE was provided in a full range of sizes for women, based on high street standard sizes, to ensure all members of the team had the right clothing. This extended to maternity PPE being available and the unique design, development and manufacture of culturally sensitive PPE for women of all religions in the team.

\section{Collaborative readiness reviews}

As described above, collaborative reviews were held prior to mobilising at each site to ensure that the plans were well developed and understood by all parties, and that everyone was aligned on the standards to be adopted. This process was continued into the main construction activities through a 'readiness' review process. This has been applied to all new construction activities that were assessed as being high risk, safety critical or programme critical.

The readiness review is a collaborative approach between main contractor and project manager, involving designers and specialist contractors as needed. The presentation and review cover all aspects of the planning for the work activity, including:

- permanent works and temporary works design

- methodology, construction sequence and key risk management, including documentation of these into risk assessments and method statements - of critical importance is the involvement of the workforce and supervisors in developing the plans, and having a clear plan on how the work will be briefed to the site teams

- site layout, organisation and logistics

- consents, approvals and arrangements for environmental protection
- team organisation, supervision, resources, competence, working hours and fatigue management

- quality control and assurance, including inspection and test plans

- emergency arrangements

- lessons learned from previous similar work on the programme, and how they have been incorporated.

Previous projects have adopted such reviews but there was a tendency for them to become highly rehearsed presentations to senior management, which loses the value in being able to challenge and discuss the detail of the work that is planned. The approach on Tideway was to hold these in a collaborative format, with senior management engagement and support, but enabling constructive critique and agreement of improvements to the plans to achieve joint agreement on the planned work.

\section{Covid-19 pandemic restart}

Early in the Covid-19 pandemic a decision was made temporarily to stop work across the programme until the working environment could be made safe. The delivery teams completely revised and updated the operational procedures and systems of work, involving extensive consultation with sites to ensure the workforce was happy with and protected by the revised plans. The readiness review process was also used to assure the new Covid-19 working arrangements, including the following additional points

- consultation with the workforce on the new arrangements, and involvement from the supervisors and workforce in putting them in place

- travel to work, providing alternative travel options to reduce demand on public transport and revising shift patterns to avoid peak travel times

- consideration of the local community, recognising the public's concerns at the time and the potential disturbance when people were working and schooling at home

- providing enhanced emergency arrangements, including trauma first aid, recognising the increased demand on the emergency services at the time and the extended response times.

\section{Restricted and exclusion zones}

Recent major UK projects such as Crossrail have demonstrated the importance of establishing exclusion zones around equipment, activities and conditions that are unsafe for people to enter. These are now used as a matter of course on sprayed concrete lining tunnelling works to protect people from unsupported excavation faces and sprayed concrete that has not yet gained strength.

The concept has been extended across all Tideway sites, both above ground and below ground, to control access to potentially unsafe areas. Red exclusion zones are established where personnel must not enter (e.g., around operating machinery), orange restricted zones are used for working areas that only authorised personnel can access and green zones are used for pedestrian access around site. 


\section{Lifting operations}

Lifting operations within shafts represent a particular situation where it is critical to ensure personnel do not enter under suspended loads (Figure 6). Exclusion zones were established for all shafts and clearly communicated to the teams, with lifting teams ensuring that they were implemented prior to starting to lift a load.

More generally, lifting operations have been a cause of injuries on previous projects when slinger and signallers were in close proximity to loads that were being lifted or landed, which then moved unexpectedly. A campaign was created on this entitled 'I'm in a safe place', encouraging slinger and signallers to confirm that they are in a place of safety before signalling that the lift can start.

\section{Transformational health and safety group}

Throughout the programme, the transformational health and safety group has continued to meet regularly to review health, safety and well-being performance and trends, to look ahead to upcoming activities and risks, to share thinking and experience, and to agree actions to enhance the safety and well-being of all of the teams.

As explained earlier, initially the group was focused on establishing the standards that would be applied to start out with the best health and safety performance. As the programme developed this transitioned into reviewing

- where safety performance had been excellent, and the planning, arrangements and actions that had led to this

- issues, near misses and incidents, and the learning from them to prevent recurrence

- the upcoming activities and risks, and sharing planning and experience to manage the risks effectively.

The group has endeavoured to keep looking ahead at future stages of construction, alongside specialised working groups to look at specific activities. Teams covering various areas - occupational health and well-being; lifting operations; marine construction and logistics; tunnelling; and mechanical, electrical, instrumentation, control and automation - have met regularly to share their planning and agree common approaches.

\section{Change management and step back}

Early in the programme there were some observations of unsafe conditions and incidents and near misses that occurred where the root cause was related to management of change. Typically, these incidents arose where a situation on site was not as expected, and the team's response to that introduced risk as a result of not taking time to review the changed situation and re-plan accordingly.

To address the issue, the step-back principle was adopted across the programme, based on the approach used within Jacobs. This encourages all the team to step back when a situation changes or is not as expected, to review the new risks, discuss them with the team and agree a new plan prior to continuing.

Just the process of stopping and discussing can invoke the deeper thinking needed to adapt safely to the situation presented. This has been widely used and communicated through briefings, cards and posters, and is now an integral part of the language of working on the programme.

\section{Incident investigation}

Despite all the focus and efforts to ensure proactively the health and safety of the workforce, unfortunately near misses and incidents have occurred. A consistent approach has been adopted across the programme to reviewing and investigating these to ensure the causes are understood and actions are devised, agreed, communicated and embedded to prevent future recurrence. This is especially important as all sites on the project are undertaking similar activities, and incidents on one site could occur elsewhere if not managed.

Fundamental to the success of the incident investigation process is the culture. Clearly, the team needs to share details of what happened and what led to it without fear of criticism or reprisal. This has to be achieved through the behaviours of senior management, and has been guided by experience from industries where learning from accidents is well developed (Syed, 2016). Investigations and reviews are conducted in such a way that teams and people are not criticised for reporting safety incidents and the circumstances that led to them, but are seen as presenting an opportunity to learn from genuine errors and mistakes to implement improvements.

In the immediate period after an incident, the affected team has to manage the issues and obtain the relevant information and it needs to have time to do this. The first serious incident event review with senior management is therefore held $24 \mathrm{~h}$ after an incident. This is to review the facts surrounding the incident, to assure that people are being looked after and supported, and to agree any actions that need to be taken immediately to prevent recurrence. The stage 1 review is also used to agree the terms of reference of the incident investigation, and to decide any immediate programme-wide safety alerts that are required to make sure all teams are aware of what happened.

The stage 2 review is then held after 7 days (or longer if required), when the investigation is complete and the root causes established. At this stage the affected team will be able to present its completed

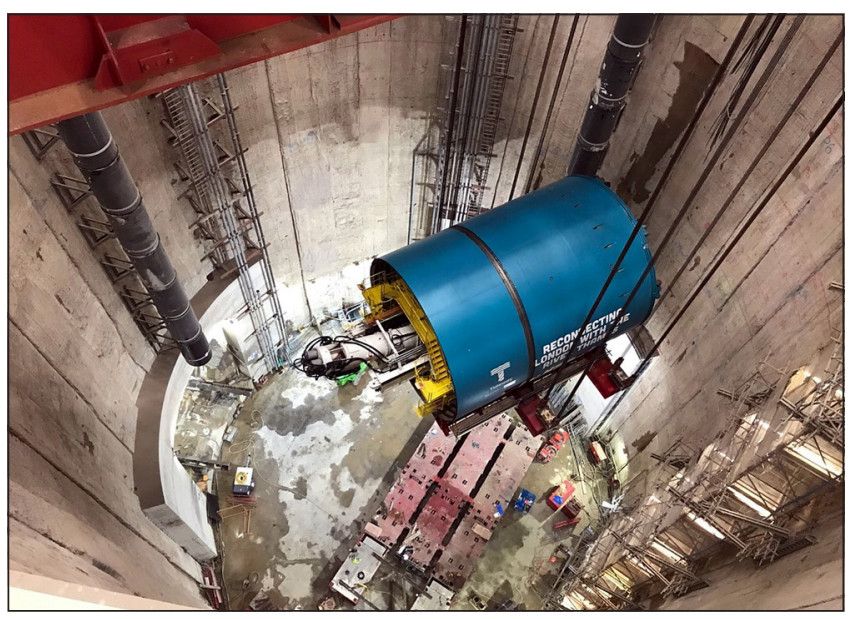

Figure 6. Exclusion zones are established in shafts before lifting operations 


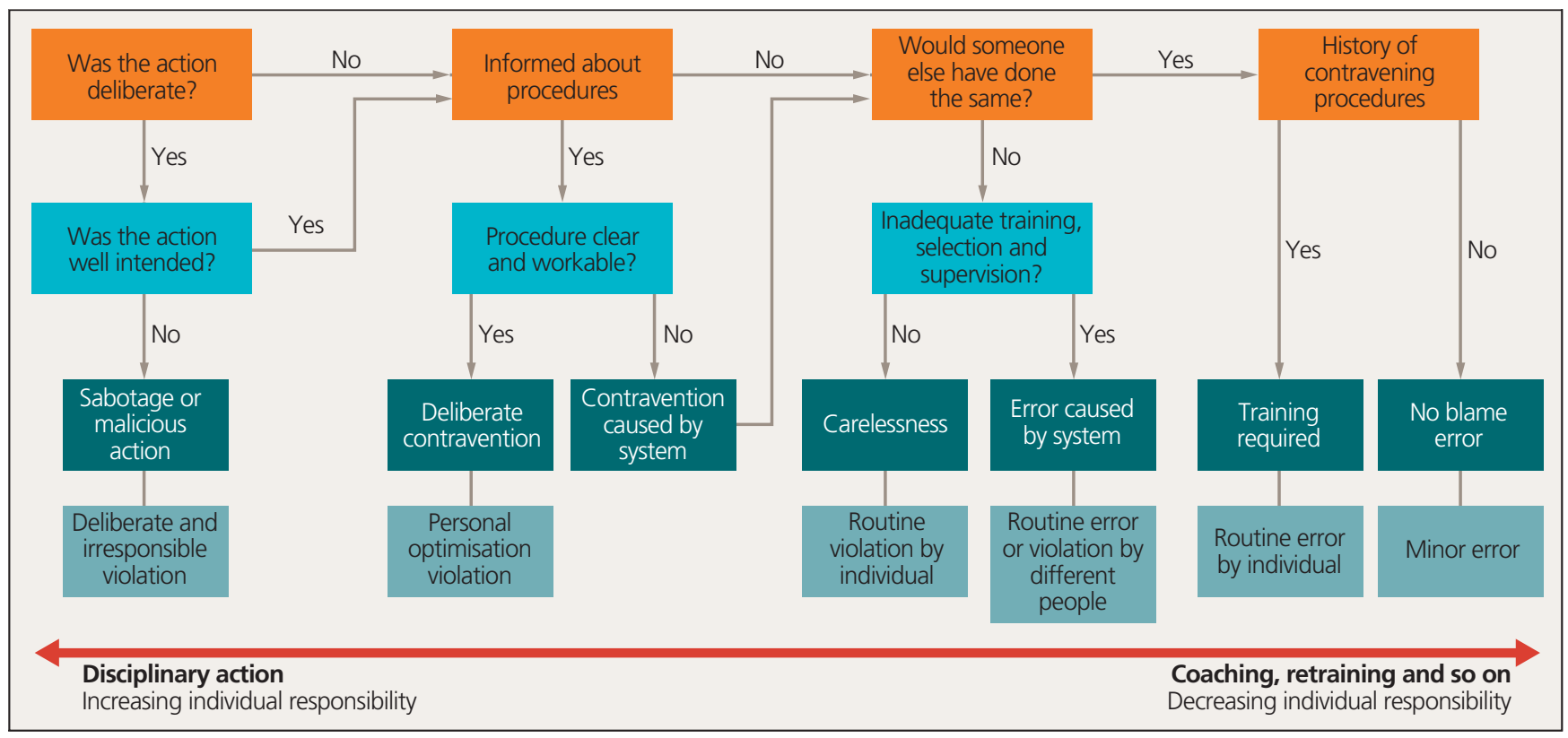

Figure 7. 'Just and fair culture' flow chart balances disciplinary action with the need for improvement

actions and future action plan to address the root causes, and for senior management to consider and approve this as well as agree any additional support to be provided to the team. The team will also agree whether a lessons-learned document should be issued across the programme to inform teams on other contracts of how the situation occurred. The team will then follow up to provide confidence that the findings and learning have been briefed out and embedded in future work. For example, lessons learned can be used in the readiness reviews for new activities and the safety alerts are used in safety briefings.

\section{Just and fair culture}

It is understood that people need to be accountable for their actions and, while the culture needs to support open sharing of details of unplanned situations so that lessons can be learned, any wilful disregard of safety arrangements needs to be addressed. To get this balance right, the transformational health and safety group agreed a 'just and fair culture' approach (Figure 7), and this forms a key component of the main contractors' health, safety and wellbeing strategy.

Where someone has made a genuine mistake, or if an error is caused by the procedures or the system of work, then the focus is on improving the systems and processes and education of the team. However, the just and fair culture provides for disciplinary action where someone has deliberately violated clear safety rules.

\section{Mental well-being}

From the start of the delivery phase in 2015 , there has been a strong focus on mental well-being alongside traditional health and safety. These are all very much complementary. Fundamentally, the culture of caring means looking out for each other as friends, caring about a whole person and not just their physical health and safety. Poor mental health can lead to distraction and pressure, and this can easily lead to accidents. It is therefore clear that looking after colleagues' mental health is a basic obligation and one that supports safety on site.

Tideway has been a strong supporter of Mates in Mind (2021) and has undertaken mental health training across the programme. This includes 'start the conversation' general training for everyone, specific training for supervisors and managers, and the full mental health first-aider qualification. Alongside these the programme has regular events and discussions to remind people that mental health issues are extremely common, to encourage them to talk if they do have problems and to look out for colleagues. This was particularly challenging through the Covid pandemic, but the teams have endeavoured to maintain that communication both on site and with people working remotely.

It is clear through the programme so far that increasing attention to mental well-being, coupled with a culture of inclusion, continues to drive everyone to look out for each other and hence further enhance their focus on keeping people safe and healthy.

\section{Transport logistics}

The programme's attitude to health and safety is that responsibility does not stop at the site gate. The responsibility extends to protect the safety of everyone affected by programme operations, both locally around the sites and on logistics routes to and from the sites.

Heavy goods vehicles servicing major construction projects in urban environments increase risks to vulnerable road users, such as cyclists and pedestrians. Being located on the Thames gave a great 
opportunity to use the river for logistics, and from the outset the programme has endeavoured to maximise this opportunity to reduce the volume of road traffic servicing the construction sites (Figure 8). It was obvious to remove excavated materials from the main tunnels and to deliver the precast concrete segments by river, but a 'more by river' initiative was used to identify further opportunities. This realised a range of additional materials to be delivered by river, including temporary works for cofferdams, prefabricated reinforcement, aggregates and site accommodation cabins.

To date, 500000 heavy goods vehicle movements have been taken off London's streets through using the river for transport, with resulting safety and environmental benefits. However, this has created a huge increase in the volume of river traffic, and specific requirements were set out in the contracts to ensure this could be done safely. These included a requirement for all marine operators to have a certified safety management system; to prepare vessel passage plans; to have navigational risk assessments to integrate the marine movements across all the programme; and to ensure effective communications with the river regulators. In addition, there were leading-edge requirements for competence and training of the marine crews, including demonstration of capability through a purpose-built marine simulator covering both normal operational and emergency situations.

A marine health and safety forum was established across the programme, providing the opportunity to share best practice and to learn from incidents that occurred on marine operations and more widely in the marine supply chain. This has been very effective in generating collaboration across the marine teams and pursuing best practice. An example was a marine version of the interactive safety induction that was developed as behavioural safety training for marine crews.

There is still a requirement for road logistics - for example, for ready mixed concrete, excavated materials removal and general logistics at the sites that do not have river access. The programme has specified high standards for heavy goods vehicles and road logistics operations. This includes requirements for site access routes; design and safety auditing of site access points; planning and coordination of deliveries; and for hauliers to obtain Freight Operator Recognition Scheme (FORS, 2021) membership.

In addition, there are specified requirements for fitting vehicle safety equipment to heavy goods vehicles (e.g., cameras, additional mirrors, proximity warning systems and side under-run guards) and for training drivers in safe urban driving. Further to this, through collaboration with the main contractors, the programme has also secured the use of direct-vision lorries for a number of deliveries, further reducing vulnerable road user risk (Figure 9).

\section{Recognising excellence and sharing best practice}

It is often said that good safety is the presence of positives as much as the absence of negatives. While it is essential to investigate near misses and incidents, it is important also to share best practice and recognise excellence. As noted above, at the transformational health and safety group the teams regularly present work that has been completed safely, and explain how that was achieved. There are various forums across the programme that also do the same at

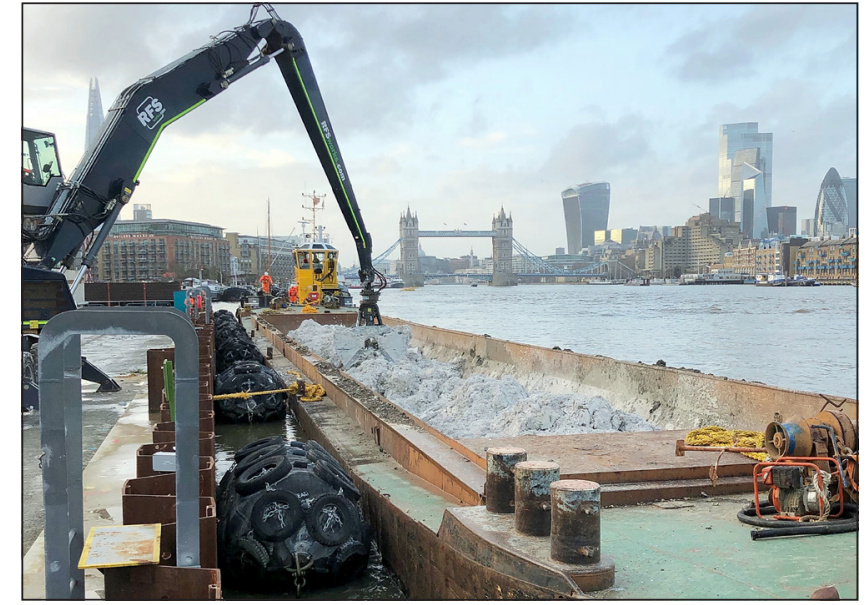

Figure 8. Marine logistics have been used extensively to service the riverside construction sites

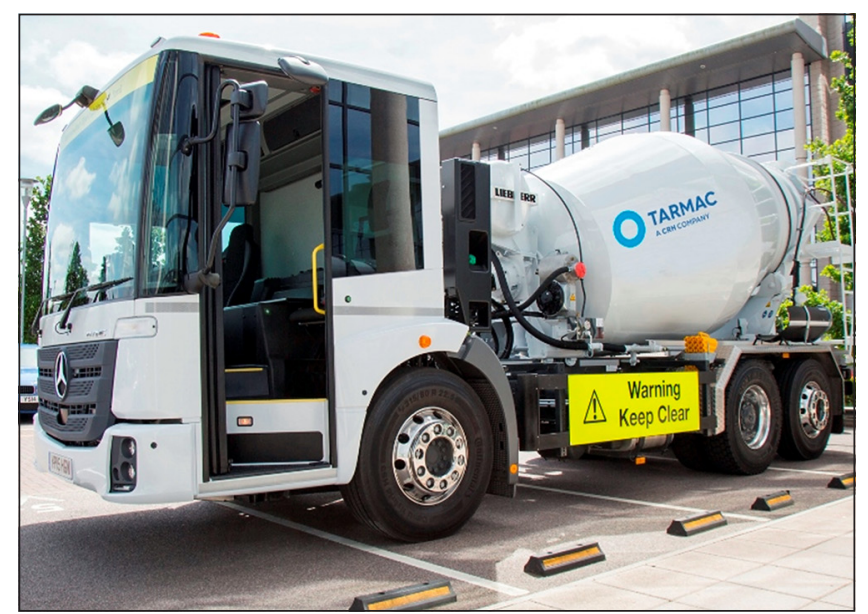

Figure 9. Safer direct-vision lorries are being used on the programme

different levels of detail, such as the specific lifting forum and the more general lessons learned forum.

The aim was to recognise and celebrate the good work being done every day, and to ensure that conversations around safety were positive wherever that was possible. A delivery awards scheme was designed to achieve that. Every month each site selects and puts forward the six things it is most proud of in relation to health, safety, well-being, quality, environment and sustainability under the following categories: safe workplace, leadership, communications and engagement, competence, performance improvement, and health and well-being.

Each month the best are selected and recognised in programme newsletters, and each quarter the team that has been most proactive in implementing and sharing best practice is awarded a quarterly delivery award (Figure 10). This includes a cash award that the site team can use to jointly celebrate their achievement. Equally importantly, details of all of the best-practice submissions are shared across the programme and the site teams are regularly reviewing 
these to see what they can adopt from elsewhere. This has become a great example of marginal gains in practice in the construction industry, where the cumulative effect of all best practice is really helping to keep people safer and healthier.

Monthly and quarterly winners are also considered for annual awards. Teams across the programme are encouraged to prepare submissions in the following categories: carbon initiative; environmental innovation; occupational health and well-being; communication and engagement; health, safety and well-being initiative; and health, safety and well-being in marine.

A panel of judges shortlists the entries and members of the senior leadership team agree the winners and present the awards at an evening event, celebrating the success of individuals and teams. In addition, the judges consider individual and team contributions to the health, safety and well-being programme including young person of the year, sub-contractor of the year, site of the year and joint venture of the year.

The awards conclude with the prestigious chairman's excellence award, which recognises an individual who has demonstrated transformational standards of personal leadership in health, safety and well-being.

\section{Conclusion}

At the start of the Tideway programme, the delivery team set out to deliver a transformational approach to health, safety and well-being by doing things differently and better. This was defined by rigorously ensuring that high standards were implemented, by seeking and adopting best practice and by creating an environment that promoted innovation and learning.

At the heart of the approach is collaboration right across the programme, between all organisations and through all parts of the team. It is underpinned by a fundamental belief that health, safety and well-being is everyone's responsibility, and that everyone will succeed (or fail) together. When challenges have been faced, all parts of the team have leant in to finding solutions and learning lessons together.

The other critical ingredient has been leadership. Programme leaders are totally committed to keeping people healthy and

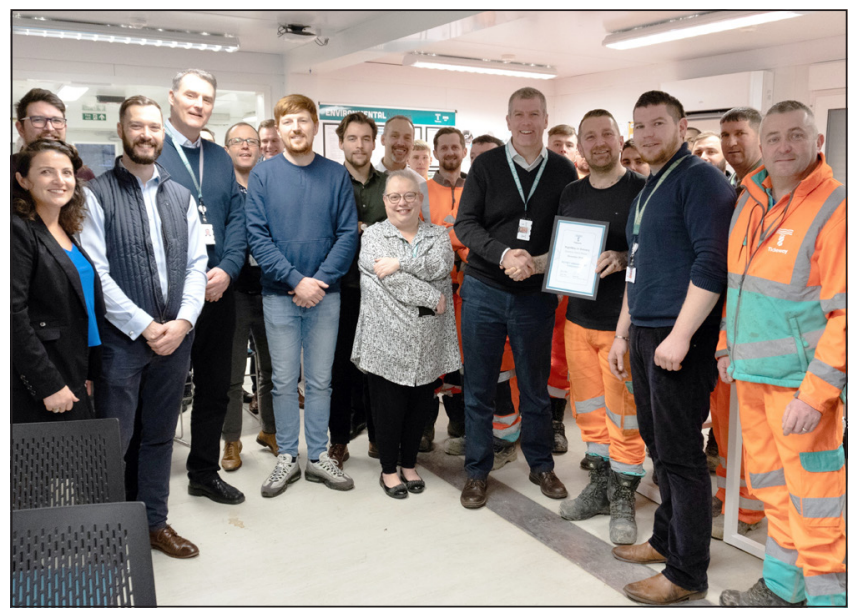

Figure 10. Site team being presented with a quarterly delivery award safe, not compromising on safety and well-being and continually pushing forward the approach to do the best possible. Leaders and supervisors throughout the organisation are approachable and accessible, and engagement with the workforce is a critical part of the safety culture. A key part of the strategy throughout the programme has been involving the supervisors and workforce in planning work and in key decision making.

At the end of 2021, Tideway was approaching $75 \%$ complete. The tunnelling work was nearing completion, all the shafts had been fully excavated, the secondary linings to the shafts and tunnels were progressing and the hydraulic structures to channel sewage from the Thames Water network into the tunnel were well advanced. The safety performance on site so far has been very good, particularly in terms of engagement, culture, site organisation and safety controls.

There have been incidents and accidents, and people have been hurt, but these have been used to continually learn and to reinforce the drive towards excellence. The work ahead is to complete the civil engineering structures and to move on to the mechanical, electrical, instrumentation, control and automation installations; architectural finishes; landscaping; and testing and commissioning.

The programme is on track to complete the remaining $25 \%$ to the same high standards as the first $75 \%$, and the core priority remains to drive excellence in health, safety and well-being right through to completing the mission to clean up the River Thames.

\section{References}

Alder A (2021) Super sewer: safely progressing London's Tideway tunnel through a global pandemic. Proceedings of the Institution of Civil Engineers - Civil Engineering 174(2): 51, https://doi.org/10.1680/ jcien.2021.174.2.51.

Alder A and Appleton M (2017) Super sewer: an update on the Thames Tideway tunnel project in London. Proceedings of the Institution of Civil Engineers - Civil Engineering 170(3): 100, https://doi.org/10.1680/ jcien.2017.170.3.100

Bazalgette JW (1865) On the main drainage of London, and the interception of the sewage from the River Thames. Minutes of the Proceedings of the Institution of Civil Engineers 24: 280-314.

Costes E, Jewell P, Michel C and Pogu F (2018) Lee tunnel project - the first step toward a cleaner River Thames. Proceedings of the Institution of Civil Engineers - Civil Engineering 171(2): 69-76, https://doi.org/10.1680/ jcien.17.00044.

FORS (Freight Operator Recognition Scheme) (2021) https://www.fors-online. org.uk (accessed 15/12/2021).

Haliday S (2001) The Great Stink of London: Sir Joseph Bazalgette and the Cleansing of the Victorian Metropolis. The History Press, Stroud, UK.

HMG (Her Majesty's Government) (2015) The Construction (Design and Management) Regulations 2015. The Stationery Office, London, UK, Statutory Instrument 2015 No. 51

Mates in Mind (2021) https://www.matesinmind.org (accessed 15/12/2021).

Stride $P$ (2016) Super sewer: an introduction to the Thames Tideway tunnel project in London. Proceedings of the Institution of Civil Engineers - Civil Engineering 169(2): 51, https://doi.org/10.1680/jcien.2016.169.2.51.

Stride P and Bazalgette P (2019) The Thames Tideway Tunnel: Preventing Another Great Stink. The History Press, Stroud, UK.

Syed M (2016) Black Box Thinking: Marginal Gains and the Secrets of High Performance. John Murray, London, UK. 